\title{
Insight into the Attitudes of Speakers of Urban Meccan Hijazi Arabic towards their Dialect
}

\author{
Sameeha D. Alahmadi \\ Northumbria University, UK \\ Newcastle City Campus, 2 Ellison P1, Newcastle upon Tyne, NE1 8ST, UK \\ E-mail: sameeha.alahmadi@northumbria.ac.uk
}

Doi:10.7575/aiac.alls.v.7n.2p.249

URL: http://dx.doi.org/10.7575/aiac.alls.v.7n.2p.249
Received: $26 / 12 / 2015$

Accepted: 08/02/2016

\begin{abstract}
The current study mainly aims to examine the attitudes of speakers of Urban Meccan Hijazi Arabic (UMHA) towards their dialect, which is spoken in Mecca, Saudi Arabia. It also investigates whether the participants' age, sex and educational level have any impact on their perception of their dialect. To this end, I designed a 5-point-Likert-scale questionnaire, requiring participants to rate their attitudes towards their dialect. I asked 80 participants, whose first language is UMHA, to fill out the questionnaire. On the basis of the three independent variables, namely, age, sex and educational level, the participants were divided into three groups: old and young speakers, male and female speakers and educated and uneducated speakers. The results reveal that in general, all the groups (young and old, male and female, and educated and uneducated participants) have a sense of responsibility towards their dialect, making their attitudes towards their dialect positive. However, differences exist between the three groups. For instance, old speakers tend to express their pride of their dialect more than young speakers. The same pattern is observed in male and female groups. The results show that females may feel embarrassed to provide answers that may imply that they are not proud of their own dialect, since the majority of women in the Arab world, in general, are under more pressure to conform to the overt norms of the society than males. Therefore, I argue that most Arab women may not have the same freedom to express their opinions and feelings about various issues. Based on the results, the study concludes with some recommendations for further research.
\end{abstract}

Keywords: sociolinguistics, language attitudes, dialectology, social variables, Urban Meccan Hijazi Arabic

\section{Introduction}

Language is the main tool used by humans for communication; it is a prominent social force whose function is not a mere transfer of information. That is, language can give insight into both personal and social aspects of its speakers (Obiols 2002). For instance, interlocutors can make judgements about each other, relating to personality, social status, educational background, etc. through observing the addressee's dialect, vocabulary, intonation, among other aspects. Attitude is defined by Ryan and Giles (1982: 7) as "any affective, cognitive or behavioural index of evaluative reactions toward different language varieties or speakers". For Obiols (2002), attitude is a mental reaction towards a particular thing that functions as a link between opinion and behaviour. Examining speakers' attitudes towards their language or dialect is of great significance in the field of sociolinguistics (Williams et al. 1976; Romaine 1980; Dittmar and Schlobinski 1988; Preston 2002; Wardhaugh 2002; among others). Speakers' attitudes towards their language or dialect can give insight into: (1) speakers' linguistic behaviour; (2) the language/dialect they choose speak in multilingual or various speech communities; (3) language/dialect prestige; and (4) language/dialect loyalty (Obiols 2002). In this area, various studies have attempted to examine speakers' attitudes towards their language/dialect. However, little attention has been given to speakers' attitudes towards Arabic in general, and Urban Meccan Hijazi Arabic (UMHA) in particular. The current study aims to bridge this gap; specifically, it aims to examine the attitudes of speakers of UMHA towards their dialect and determine whether social variables such as age, sex and educational level affect the speakers' perception of their dialect.

\section{Previous research on language attitudes}

The tendency to investigate speakers' attitudes towards their language or speech variety has started as early as the 1930s. The first study to be conducted in this area was carried out by none other than Thomas Hatherley Pear (1931). In his study, Pear examined whether the speaker's voice is able to generate enough cues to carry out a reliable personality evaluation. The results of his study revealed that the judgements of personality are not reliant on any accurate reflection of personality hidden in the voice of the speaker, rather the judgments had the tendency to stereotype speaker's personality in terms of the sound of his/her voice (Pear 1931: 30). Since Pear's study, research of speakers' perception and attitudes towards their language or speech variety has begun to take momentum (McClelland 1961; Baker 1976; Migunda Attyang 2007; Leong 2014; among others). Studies addressing language attitudes have demonstrated that the status of a particular language or speech variety relies on the attitudes of individuals towards its characteristics, uses, 
cultural aspects, such as songs and proverbs (see Zibin and Altakhaineh 2014). According to Baker (1976), there are two factors related to language attitude in sociolinguistic research, namely, instrumental and integrated orientation. The former refers to a self-oriented and individualistic attitude to language that has a cognitive overlap with the individual's need for achievement (McClelland 1961). On the other hand, the latter is socially and interpersonally oriented; this type of attitudes arises from a need for affiliation (Baker 1976). However, such attitudes are not constant; they may change gradually overtime for various reasons. These types of attitudes are referred to in the course of the discussion.

In one study that focused on speakers' attitudes towards their language, Migunda Attyang (2007) investigated speakers' perceptions of Sheng, a stigmatised hybrid speech variety spoken in Nairobi as well as other urban areas of Kenya. Migunda Attyang (2007) focused on speakers' beliefs concerning Sheng's structure, function and its use by different age groups and different social-economic-status individuals. She discovered that when the participants were given both positive and negative statements regarding Sheng, negative statements prevailed in comparison with the positive ones. What was interesting about her results was that young speakers were the ones whose responses were most negative. Young speakers were keener on speaking a speech variety that is not stigmatised in their community and in other communities as well.

In another recent study, Leong (2014) examined speakers' attitudes towards Mandarin, in light of the Singapore Government's campaign in 1979 to persuade dialect speakers to abandon their Chinese dialects in favor of Mandarin. The sample of the study consisted of 126 dialect speakers. Leong (2014) elicited the data through a self-administered survey, which was designed to determine dialect speakers' attitudes towards the use of Mandarin in various domains. The results of the study demonstrated that despite the fact that dialect speakers have abandoned their original dialects, started using Mandarin and agreed on the continuation of the Mandarin campaign launched by the Singapore government, they conceived of Mandarin as having a lower status and importance compared to English. The reason for this change is that English has become a dominant language in Singapore; it is mainly associated with social identity and modernity. Thus, speakers' choice of the language/dialect they prefer to speak is, arguably, related to affiliation and language prestige.

Alahmadi (2015: 38) indicated that Urban Meccan Hijazi Arabic (UMHA), a dialect of Arabic spoken in Mecca, Saudi Arabia, has been greatly influenced by other languages through language contact. Mecca is regarded as a holy city to Muslims around the globe; millions of Muslims travel to Mecca every year to fulfil one of the pillars of Islam, namely, pilgrimage. As a result of communicating with Muslims, who stay in Mecca for religious purposes, an abundance of loan words from various languages, such as Turkish, Persian, Urdu, Italian, Spanish and many more found their way into UMHA. The lexical diversity of UMHA has transformed it into a unique variety of Arabic. Hence, one may argue that examining speakers' attitudes towards UMHA can provide insight into the speakers' cognitive and linguistic behaviour. To the best of my knowledge, so far such a study has not been undertaken. Thus, the current study is motivated by this suggestion. In particular, this study seeks answers to the following research questions:

1) What are speakers of UMHA attitudes towards their dialect?

2) Do the participants' age, sex and educational level have an impact on their attitudes towards UMHA?

\section{Methodology}

\subsection{The participants}

This study involved 80 speakers of Urban Meccan Hijazi Arabic, who live in Mecca, Saudi Arabia. They were all born in Mecca and have not lived in another country for more than three months (see Alahmadi 2015). The participants were selected randomly from a population, reflecting the three independent variables, i.e. age, sex and educational level. According to Meyerhoff et al. (2015), in a simple random sampling, all individuals can be chosen to participate in the study equally. Thus, this technique reduces human bias and ensures that the selected sample represents the population, i.e. residents in Mecca.

The participants were divided into three groups based on the three independent variables: 35 young speakers (20-45 years old) and 45 old speakers (46-70+ years old) based on age, 40 male speakers and 40 female speakers based on sex and 30 uneducated speakers and 50 educated speakers based on educational level (see Alahmadi 2015). These three social variables have proven their influence on various aspects related to linguistic behaviour (see Eckert 1989; Altakhaineh and Rahrouh 2015) and social behaviour (see Tagliamonte 2006; Migunda Attyang 2007; among others).

\subsection{Instrument}

In order to provide accurate answers to the two research questions, I designed a 26-item questionnaire (see Appendix 1). Questionnaires have been widely used as a data elicitation tool in the field of sociolinguistics, since they can elicit a substantial amount of data in a short time as well as provide insight into individuals' linguistic and social behaviour, especially in certain social situations. They also demonstrate speakers' attitudes towards various issues related to language and society (Meyerhoff et al. 2015: 71). The questionnaire employed in the current study is divided into two sections: section 1 was devoted to collecting general information about the participants, i.e. their age, sex, educational level, occupation, etc. this section is important, because it provides the necessary information about the participants which may influence their attitudes towards UMHA. Section 2 is a 5-point-Likert-scale questionnaire, containing questions about the participants' attitudes towards their dialect, and whether they want to preserve it and use it continuously. This may give an idea about their opinions and feelings towards their mother tongue and whether the previously-mentioned social variables contribute to their answers. Other studies have utilised this data elicitation tool to 
test other aspects of linguistic behaviour (see Altakhaineh and Zibin 2014). It should be noted that participation in this study was completely voluntary; the participants who chose to take part in the study signed a consent form.

With respect to data collection, I distributed the questionnaire to residents of Mecca, who were in the streets at the time of data collection. This may show that the selection of the participants was indeed random. I also kept my distance from the participants at the time of data collection to lessen the effect of the observer's paradox (1972: 92).

\section{Results and discussion}

This section reports on the participants' results on section 2 that deals with their attitudes towards their dialect (see Appendix 1). Starting with the first two groups, i.e. young and old participants, the results showed that their results were similar on some questions but not on others. For example, when asked to express their agreement or disagreement on the question: Young people in Mecca speak the dialect as well as old people, $86 \%$ of young speakers and $93 \%$ of the old speakers answered: disagree. The two age groups provided similar answers, but for different reasons. Possibly, the young speakers provided such as answer, because they believe that being old means that someone had lived for a longer time, and thus had wider experience. Therefore, they indicated that old people speak UMHA better than them. Young people may also measure one's knowledge of his/her dialect by how many old words he/she knows. Being unable to know the meaning of some old words in UMHA may make them believe that they do not know the dialect as well as the old speakers do. From another perspective, the old speakers may have indicated that the young speakers do not know the dialect as well as they do, because they may believe that young speakers are more eager to learn other languages, such as English. Thus, young people may not be as interested as they are in preserving the dialect (cf. Migunda Attyang 2007). Additionally, the older participants indicated that they do not understand many words young people use these days. They indicated that many words used by young people these days either come from other languages or are coined by them. Therefore, the old participants may believe that young participants are not as interested as they are in recording and preserving the dialect.

The following table presents the answers of the two groups on some questions.

Table 1. The participants who answered agree or strongly agree on some items

\begin{tabular}{llll}
\hline No. & The item in the questionnaire & Younger & older \\
\hline 1. & $\begin{array}{l}\text { We should keep speaking Meccan Hijazi Arabic } \\
\text { everywhere not only in Mecca. }\end{array}$ & $97 \%$ & $98 \%$ \\
\hline 2. & $\begin{array}{l}\text { We should use Meccan Hijazi orthography to } \\
\text { preserve Meccan songs, proverbs, etc. }\end{array}$ & $91 \%$ & $96 \%$ \\
\hline 3. $\quad \begin{array}{l}\text { If there was no Meccan Hijazi dialect in use, there } \\
\text { would be no Meccan Hijazi culture. }\end{array}$ & $94 \%$ & $100 \%$ \\
\hline 4. $\quad \begin{array}{l}\text { I think being a speaker of Meccan Hijazi dialect is } \\
\text { better than being a speaker of any other dialect. }\end{array}$ & $86 \%$ & $96 \%$ \\
\hline 5. & $\begin{array}{l}\text { I think we should have TV programmes in Meccan } \\
\text { Hijazi dialect. }\end{array}$ & $80 \%$ & $98 \%$ \\
\hline Total mean of answers & $90 \%$ & $98 \%$ \\
\hline
\end{tabular}

Table 1 shows that a big number of both the older (98\%) and the younger participants (90\%) agree on using and preserving UMHA in their daily conversation as well as start writing it. These answers could be due to two reasons; firstly, even though young people may want to learn English and other European languages so that, they can be perceived as prestigious (see Baker 1976) they still want to use UMHA. For instance, on the questions:

- If you want to marry, you would prefer your spouse to be a Meccan Hijazi speaker.

- If your children want to marry, you would prefer his/her spouse to be a Meccan Hijazi speaker.

$83 \%$ and $89 \%$ of the young participants answered agree or strongly agree, respectively. This may show that they have positive attitudes towards their dialect, mainly, since it expresses their uniqueness, affiliation and solidarity (cf. Baker 1976; Leong 2014). For instance, it has been observed that many young and old speakers attempt to preserve the dialect by continue using UMHA proverbs. Also, instead of using MSA in writing, many young people use UMHA in writing, as it has been noticed in the social media networks such as Twitter and Facebook. These results may show that many old and young people alike have the desire to use and preserve their dialect.

Secondly, it can be argued that some participants, especially young participants, may have felt embarrassed to provide answers that may imply that they are not proud of their own dialect. They may have felt worried about being perceived as people who love other languages and cultures more than they love their own. Even though they have not revealed their identities, they may have still felt worried and embarrassed about expressing their true feelings. In the Arab culture in general, most people worry about what others think. They fear that if people think that they are deviating from the norms that are prevalent in the society, they would be considered outcasts and no one would speak to them. This applies mainly to women, which takes us to the answers provided by males and females. 
The results reveal that the answers provided by both males and females, regarding their attitudes towards their dialect have some similarities and differences. For instance, on the question: I think that males speak Meccan Hijazi Arabic better than females. The male and female answers were as follows:

- Female: $75 \%$ answered disagree or strongly disagree

- Male: $88 \%$ answered agree or strongly agree

$75 \%$ of the female participants may have disagreed, because they may think that they are the ones who stay at home most of the time. Hence, most of their communication is done with other women, who also live in Mecca and who speak UMHA. They have their own dense networks, which consist of local Meccan women. Most women in Mecca are housewives; thus, they spend most of their time at home. In contrast, men spend most of their time outside the house working. Due to pilgrimage, men communicate with many nationalities. Therefore, according to women, men's dialect may get affected by the languages spoken by the pilgrims. Also, women may believe that they speak the dialect better than the men, since they are the ones who take care of the children and teach them how to speak. In the Arab society in general, it is the responsibility of women to take care of the children and see to their needs. The men's job is to go to work and provide for the family. Thus, teaching children their mother tongue may be regarded as a sufficient reason for the women to claim that they speak UMHA better than men.

On the other hand, $88 \%$ of the men agree that they speak the dialect better than the females, because they may believe that females want to speak like women in Jeddah, a coastal city in Saudi Arabia. Therefore, women may not speak UMHA as well as they do. Some Meccan young women may believe that speaking the dialect spoken by young women in Jeddah may make others perceive them as prestigious (cf. McClelland 1961 and Leong 2014). Therefore, many men believe that they can speak the dialect better than Meccan women, since the latter's dialect may have been influenced by the dialect spoken in Jeddah, while theirs have not. In contrast, for them, working all day in Mecca means that they have more opportunities to speak the dialect more than women.

With regard to their attitudes towards their dialect, the following table shows some of their answers:

Table 2. The participants who answered agree or strongly agree on some items

\begin{tabular}{|c|c|c|c|}
\hline No. & The item in the questionnaire & Male & Female \\
\hline 1. & $\begin{array}{l}\text { We should keep speaking Meccan Hijazi Arabic } \\
\text { everywhere not only in Mecca. }\end{array}$ & $88 \%$ & $83 \%$ \\
\hline 2. & $\begin{array}{l}\text { We should use Meccan Hijazi orthography to } \\
\text { preserve Meccan songs, proverbs, etc. }\end{array}$ & $93 \%$ & $85 \%$ \\
\hline 3. & $\begin{array}{l}\text { If there was no Meccan Hijazi dialect in use, there } \\
\text { would be no Meccan Hijazi culture. }\end{array}$ & $95 \%$ & $93 \%$ \\
\hline 4. & $\begin{array}{l}\text { I think being a speaker of Meccan Hijazi dialect is } \\
\text { better than being a speaker of any other dialect. }\end{array}$ & $80 \%$ & $85 \%$ \\
\hline 5. & $\begin{array}{l}\text { I think we should have TV programmes in Meccan } \\
\text { Hijazi dialect. }\end{array}$ & $75 \%$ & $80 \%$ \\
\hline Tota & ean of answers & $87 \%$ & $86 \%$ \\
\hline
\end{tabular}

Table 2 demonstrates that both the male (87\%) and the female $(86 \%)$ participants expressed their desire to use and preserve UMHA. Both male and females participants may have provided such answers because they wanted to show their pride of speaking UMHA, the dialect spoken in the holy city. Another reason could be that they felt embarrassed; they did not want others to think that they do not care about their dialect. In particular, the majority of women in the Arab world, in general, are under more pressure to conform to the overt norms of the society. They may not have the same liberty which men enjoy. Therefore, they may not have the same freedom to express their opinions and feelings about various issues.

Finally, the educated and the uneducated participants provided similar answers on some items on the questionnaire and different answers on others. For example, on the question: I think that education plays a role in how well someone speaks Meccan Hijazi Arabic, the participants' answers were as follows:

- Educated: 90\% answered agree or strongly agree

- Uneducated: $40 \%$ answered disagree or strongly disagree

$90 \%$ of the educated participants indicated that education plays an important role in how well someone speaks UMHA. It could be because they may believe that having a university degree may enable the person to know the structure, the vocabulary and the pronunciation of the words and phrases of a certain language or dialect better than someone who is not educated. For them, such knowledge may enhance their understanding of their own dialect and, in turn improve the way they speak it. According to them, studying MSA at the university may enhance the individual's understanding of his/her own dialect, since MSA is the origin of all Arabic spoken dialects. They have also indicated that education helps the person to know the best ways to record and preserve the language. This means that they may have the ability to 
prevent the death of their dialect in the future. However, someone who had not had the chance to be taught at the university may lack such valuable skills in their opinion.

Contrarily, $40 \%$ of the uneducated participants disagreed on the fact that education plays an important role in how well someone speaks UMHA. They may think that education does not contribute to the individual's knowledge of his/her dialect, because it is the everyday practice that counts. For instance, some of them indicated that both educated and uneducated people learn the dialect from infancy. Thus, both types of people are able to speak the dialect fluently. Other participants indicated that they may even know the dialect better than the educated participants because of the nature of some the jobs they occupy, i.e. taxi drivers, tailors, mechanics, etc. Occupying these jobs may help them know the local dialect spoken in the streets, the one which they call "the true Meccan Hijazi Arabic". They have even developed special words and styles of speaking the dialect which other members of the community may not know. Thus, they may consider themselves as the authentic source of the dialect.

The following table presents the participants' answers on some items on the questionnaire that are related to their attitudes towards their dialect

Table 3. The participants who answered agree or strongly agree on some items

\begin{tabular}{llll}
\hline No. & The item in the questionnaire & Educated & Uneducated \\
\hline 1. & $\begin{array}{l}\text { We should keep speaking Meccan Hijazi Arabic } \\
\text { everywhere not only in Mecca. }\end{array}$ & $88 \%$ & $90 \%$ \\
\hline 2. $\quad \begin{array}{l}\text { We should use Meccan Hijazi orthography to } \\
\text { preserve Meccan songs, proverbs, etc. }\end{array}$ & $92 \%$ & $80 \%$ \\
\hline $\begin{array}{l}\text { If there was no Meccan Hijazi dialect in use, there } \\
\text { would be no Meccan Hijazi culture. }\end{array}$ & $96 \%$ & $93 \%$ \\
\hline $\begin{array}{l}\text { I think being a speaker of Meccan Hijazi dialect is } \\
\text { better than being a speaker of any other dialect. }\end{array}$ & $94 \%$ & $83 \%$ \\
\hline 5. $\quad \begin{array}{l}\text { I think we should have TV programmes in Meccan } \\
\text { Hijazi dialect. }\end{array}$ & $84 \%$ & $80 \%$ \\
\hline Total mean of answers & $91 \%$ & $85 \%$ \\
\hline
\end{tabular}

Table 3 demonstrates that both the educated (91\%) and the uneducated (85\%) participants expressed their desire to use and preserve UMHA. in general, one may observe that all the groups (old and young, male and female, educated and uneducated) have a sense of responsibility towards their dialect. This makes their attitudes towards their dialect positive.

\section{Conclusion and recommendations}

This study has examined the attitudes of speakers of UMHA towards their dialect. It also investigated whether social variables such as age, sex and educational level had any impact on the participants' attitudes towards UMHA. To this end, I designed a 5-point-Likert-scale questionnaire that included questions about the participants' attitudes towards their dialect and gave it to 80 speakers of UMHA, residing in Mecca. The results showed that in general, all the groups (old and young, male and female, and educated and uneducated) have a sense of responsibility towards their dialect. This makes their attitudes towards their dialect positive. Two main reasons were proposed for this attitude; firstly, the participants possibly regarded their dialect as a representative of their identity; it expresses their uniqueness, affiliation and solidarity. For instance, it has been noticed that many young and old speakers attempt to preserve the dialect by continue using UMHA proverbs. Additionally, instead of using MSA in writing, many young people use UMHA, as observed in the social media networks such as Twitter and Facebook. These results may show that many old and young people alike have the desire to use and preserve their dialect. Secondly, I argued that some participants, especially young participants, may have felt embarrassed to provide answers that may imply that they are not proud of their own dialect. In the Arab culture in general, many individuals worry about what others think. They fear that if people think that they are deviating from the norms that are prevalent in the society, they would be considered outcasts and no one would speak to them. The same behaviour is observed in women, particularly; I argued that the majority of women in the Arab world, in general, are under more pressure to conform to the overt norms of the society than males. They may not have the same liberty which men enjoy. Therefore, they may not have the same freedom to express their opinions and feelings about various issues. Finally, both the educated and the uneducated participants expressed their desire to use and preserve UMHA. The uneducated participants maintained that they are the ones who speak the true UMHA because of the nature of some the jobs they occupy, i.e. taxi drivers, tailors, mechanics, etc. These jobs help them be more familiar with the local dialect spoken in the streets of Mecca. Based on these results, it is recommended that more studies need to be conducted to test speakers' attitudes towards their language or dialect in order to give insight into their linguistic and social behaviour. 


\section{References}

Alahmadi, S. D. (2015). Loanwords in the Urban Meccan Hijazi Dialect: An Analysis of Lexical Variation according to Speakers' Sex, Age and Education. International Journal of English Linguistics, 5(6), 34-58. DOI: http://dx.doi.org/10.5539/ijel.v5n6p34.

Altakhaineh, A., and Rahrouh, H. (2015). The Use of Euphemistic Expressions by Arab EFL Learners: Evidence from Al Ain University of Science and Technology. International Journal of English Linguistics, 5(1), 14-21. DOI: http://dx.doi.org/10.5539/ijel.v5n1p14.

Altakhaineh, A., and Zibin, A. (2014). Perception of Culturally Loaded Words by Arab EFL Learners. International Journal of Linguistics, 6 (3), 1-22. DOI: http://dx.doi.org/10.5296/ijl.v6i3.4922.

Baker, C. (1976). Attitudes and language. Cleveland: Multilingual Matters.

Dittmar, N., and Schlobinski, P. (1988). The Sociolinguistics of Urban Vernaculars: Case Studies and Their Evaluation. Berlin: De Gruyter.

Eckert, P. (1989). The Whole Woman: Sex and Gender Differences in Variation. Language Variation and Change, 1, 245-267.

Labov, W. (1972). Sociolinguistic patterns. Philadelphia: University of Pennsylvania Press.

Leong, N. C. (2014). A Study of Attitudes towards the Speak Mandarin Campaign in Singapore. Intercultural Communication Studies, 23(3), 53-65.

McClelland, D. (1961). The achieving society. London: Free Press.

Meyerhoff, M., Schleef, E., and Mackenzie, L. (2015). Doing sociolinguistics: A practical guide to data collection and analysis. London: Routledge.

Migunda-Attyang, J. (2007). Attitudes towards Sheng: An Emerging Language in Nairobi. Chemichemi. International Journal of the School of Social Sciences, 4(1), 29-43.

Obiols, M. (2002). The Matched Guise Technique: A Critical Approximation to a Classic Test for Formal Measurement of Language Attitudes. Noves SL. Revista de Sociolinguistica, 1, 1-6.

Pear, T. (1931). Voice and personality. London: Wiley.

Preston, D. R. (2002). Language with an attitude. In J. Chambers, N. Schilling-Estes and P. Trudgill (Eds.) Handbook of language Variation and Change (pp. 40- 66). Oxford: Blackwell.

Romaine, S. (1980). Stylistic Variation and Evaluative Reactions to Speech: Problems in the Investigation of Linguistic Attitudes in Scotland. Language and Speech, 23, 213-232.

Ryan, E. B., and Giles, H. (1982). Attitudes towards language variation. London: Edward Arnold.

Tagliamonte, S. (2006). Analysing sociolinguistic variation. Cambridge: Cambridge University Press.

Wardhaugh, R. (2002). An introduction to sociolinguistics. 4th ed. Oxford: Blackwell.

Williams, F. N. (1976). Explorations of the Linguistic Attitudes of Teachers. Rowley: Newbury House Publishers Inc., Massachusetts.

Zibin, A., and Altakhaineh, A. (2014). Informativity of Arabic Proverbs in Context: An Insight into Palestinian Discourse. International Journal of Linguistics, 6(1), 67-83. DOI: http://dx.doi.org/10.5296/ijl.v6i1.4857.

\section{Appendix 1}

The Questionnaire

Section 1: Background information

1. Age:
a) 20-35
b) $36-45$
c) $46-70$
d) $70+$

2. Sex:
a) male
b) female

3. Place of birth:

4. Education:
a) None
b) Primary school
c) Secondary school
d) University degree
e) Higher education

5. Occupation:
a) Student
b) Labourer
c) Housewife
d) Government employee
e) Other: 
6. Place of work/study:
a) Home
b) Mecca city
c) Another city in Saudi Arabia
d) Outside the country

7. Have you ever lived outside Mecca city area?
a) Yes
b) No

8. If yes, how long?

9. Why did you go there?
a) Travel
b) Study
c) Work
d) Trade
e) Other reasons:

10. Have you ever lived for more than a month outside Mecca city area?
a) Yes
b) No

11. Do you want to work/study in places outside Mecca city?
a) Yes
b) No

Section 2: Attitudes towards Urban Meccan Hijazi dialect:

Answer the following questions:

12. Young people in Mecca speak the dialect as well as old people:

1- Strongly disagree 2-Disagree 3-Nuetral 4-Agree 5- Strongly agree

13. I prefer if Meccan Hijazi dialect has a written form:

1- Strongly disagree 2-Disagree 3-Nuetral 4-Agree 5- Strongly agree

14. We should keep speaking Meccan Hijazi Arabic everywhere not only in Mecca:

1- Strongly disagree 2-Disagree 3-Nuetral 4-Agree 5- Strongly agree

15. We should use Meccan Hijazi orthography to preserve Meccan songs, proverbs, etc.:
1- Strongly disagree
2-Disagree
3-Nuetral
4-Agree
5- Strongly agree

16. If there was no Meccan Hijazi dialect in use, there would be no Meccan Hijazi culture.
1- Strongly disagree
2-Disagree
3-Nuetral
4-Agree
5- Strongly agree

17. People in Mecca always want to speak Meccan Hijazi dialect:
1- Strongly disagree
2-Disagree
3-Nuetral
4-Agree
5- Strongly agree

18. When the dialect has more and more foreign words in it, it may not be considered pure.
1- Strongly disagree
2-Disagree
3-Nuetral
4-Agree
5- Strongly agree

19. I think being a speaker of Meccan Hijazi dialect is better than being a speaker of any other dialect.
1- Strongly disagree
2-Disagree
3-Nuetral
4-Agree
5- Strongly agree

20. If you want to marry, you would prefer your spouse to be a Meccan Hijazi speaker:
1- Strongly disagree
2-Disagree
3-Nuetral
4-Agree
5- Strongly agree

21. If your children want to marry, you would prefer his/her spouse to be a Meccan Hijazi speaker:
1- Strongly disagree
2-Disagree
3-Nuetral
4-Agree
5- Strongly agree

22. I think we should have TV programmes in Meccan Hijazi dialect:
1- Strongly disagree
2-Disagree
3-Nuetral
4-Agree
5- Strongly agree 
23. If there was, I would watch them:

1- Strongly disagree

2-Disagree

3-Nuetral

4-Agree

5- Strongly agree

24. I speak the dialect with someone I don't know, and I cannot tell if they are Meccan or not:

1- Strongly disagree

2-Disagree

3-Nuetral

4-Agree

5- Strongly agree

25. I think that males speak Meccan Hijazi Arabic better than females:

1- Strongly disagree

2-Disagree

3-Nuetral

4-Agree

5- Strongly agree

26. I think that education plays a role in how well someone speaks Meccan Hijazi Arabic:
1- Strongly disagree
2-Disagree
3-Nuetral
4-Agree
5- Strongly agree 